\title{
Article \\ Gambling-Related Harms for Affected Others: A Finnish Population-Based Survey
}

\author{
Sari Castrén ${ }^{1,2,3, * \mathbb{D}}$, Kalle Lind ${ }^{1}$, Heli Hagfors ${ }^{4}$ and Anne H. Salonen ${ }^{1,5}$ \\ 1 Health and Well-Being Promotion Unit, Finnish Institute for Health and Welfare, P.O. Box 30, \\ 00271 Helsinki, Finland; kalle.lind@thl.fi (K.L.); anne.salonen@thl.fi (A.H.S.) \\ 2 Social Sciences Department of Psychology and Speech-Language Pathology, University of Turku, \\ 20014 Turku, Finland \\ 3 Department of Medicine, University of Helsinki, P.O. Box 64, 00013 Helsinki, Finland \\ 4 Faculty of Social Sciences (SOC), Tampere University, 33014 Tampere, Finland; heli.hagfors@tuni.fi \\ 5 Faculty of Health Sciences, University of Eastern Finland, P.O. Box 1627, 70211 Kuopio, Finland \\ * Correspondence: sari.castren@thl.fi
}

Citation: Castrén, S.; Lind, K.;

Hagfors, H.; Salonen, A.H.

Gambling-Related Harms for

Affected Others: A Finnish

Population-Based Survey. Int. J.

Environ. Res. Public Health 2021, 18

9564. https://doi.org/10.3390/

ijerph18189564

Academic Editor: Icro Maremmani

Received: 21 June 2021

Accepted: 2 September 2021

Published: 10 September 2021

Publisher's Note: MDPI stays neutra with regard to jurisdictional claims in published maps and institutional affiliations.

Copyright: (c) 2021 by the authors. Licensee MDPI, Basel, Switzerland This article is an open access article distributed under the terms and conditions of the Creative Commons Attribution (CC BY) license (https:// creativecommons.org/licenses/by/ $4.0 /)$
Abstract: Aims This study explores the prevalence of being a past-year affected other (AO) of a problem gambler by gender. The aims were to study the amount and type of gambling-related harms (GRHs) for subgroups of AOs and to distinguish GRH profiles for AO subgroups. Methods A total of 7186 adults aged 18 years and over participated in the Gambling Harms Survey evaluating year 2016. The data were analyzed using descriptive statistics and binary logistic regression. Results Of all respondents, $12.9 \%$ were defined as past-year AOs (women 13.7\%; men 12.1\%). The proportion of affected non-family members (ANFs) was $8.4 \%$, and $5.6 \%$ were affected family members (AFMs). AFMs were usually women, and ANFs were usually men. Emotional, relationship, and financial harms were the most common types of harm. The odds of experiencing financial harm were highest for the 18- to 34-year-olds (OR 1.82) and for those whose partner/ex-partner had a gambling problem (OR 3.91). Having a parent/step-parent (OR 1.93) and child/stepchild (OR 3.64) increased the odds of experiencing emotional harm, whereas male gender (OR 0.50) and being an ANF (OR 0.58) decreased emotional harm. Relationship harm was evident for partners/ex-partners (OR 1.97-5.07). Conclusions GRH profiles for AO subgroups varied, which emphasizes the need for effective harm minimization strategies for those in need.

Keywords: affected others; affected family members; affected non-family members; problem gambling; gambling-related harm; population study

\section{Introduction}

The recent research scope has been broadened to look at different types of gamblingrelated harms and identify who is encountering these harms [1,2]. Based on the framework by Langham and her colleagues (2016), gambling-related harms (GRHs) are defined as any negative/detrimental consequence caused by gambling that leads to diminished health or well-being of an individual, family unit, community, or population. This is particularly true among persons close to the problem gambler [3-5]. Thus, the need for support and treatment for close ones has been acknowledged [5-9], and a profound understanding of GRHs of close ones and subtypes are needed. This study investigates GRHs exclusively based on the experiences of different subgroups of affected others with a close relationship to a problem gambler. According to Langham and colleagues, GRHs include financial harms, relationship harms, and emotional/psychological harms; the impacts on health, work, and study; and social deviance harms, such as child neglect and possible criminal acts [1]. Overall, financial, emotional, and relationship harms have been identified as the most prevalent types of GRHs for affected others [5,10,11]. GRHs for the affected others are largely similar to those of gamblers $[10,12]$. At the same time, population-based studies of GRHs among affected others are relatively scarce. 


\subsection{Prevalence of Affected Others in Different Subgroups}

The term affected other $(\mathrm{AO})$ is used to refer to persons who have or have had close ones with problematic gambling. The term $\mathrm{AO}$ does not imply relationship status or any level of concern [13]. AO is used as a synonym for the concerned significant other (CSO) of a person with a gambling problem [14-16]. Herein, the subgroups of AOs are examined from the perspective of both affected family members and affected non-family members, including friends, co-workers, neighbors, and other close persons.

The prevalence of AOs varies, drawn from epidemiological studies from 2 to 19 percent, depending on methodology, timeframe, and definitions used [14-19]. In Finland, the prevalence of AOs has increased in the past years from $13 \%$ to $19 \%[19,20]$. This is a substantial number of individuals in the population that ought to be recognized. Typically, women are affected family members and men are affected close friends [14], with the most affected age groups being 18-24 and 25-44 [15,16]. GRHs for different subgroups of AOs, may vary.

\subsection{GRHs for Affected Family Members}

The link between health issues, including a gambling problem of one's own, poor perceived health, psychological distress, and risky alcohol consumption and being an AO was clearest among the affected family members (AFMs) [5,14-18]. Likewise, with the health correlates, the amount of GRHs was the largest and most extensive among the AFMs. Particularly partners report engaging in dysfunctional behaviors such as risky alcohol consumption, smoking, overeating, and compulsive buying to cope with the distress [8].

Problem gambling affects the family as a whole. Gamblers' partners report severe emotional and psychological harms, such as feelings of extreme distress, hopelessness, and vulnerability, as well as stress-related health harms including insomnia, headaches, and high blood pressure [8,10,12,21]. Some spouses report getting extra employment or paying their partner's debts to overcome financial difficulties [15,21]. This can create tension in relationships that may manifest in arguments, mistrust, the threat of separation or divorce [16,21], and even risk of experiencing familial violence [22].

Gambler's children have an elevated risk for developing gambling problems themselves and engaging in other risky behaviors such as alcohol consumption, smoking, and substance abuse [23]. Gambling in a family affects a child's academic performance and may contribute to difficulties in school, such as behavioral and adjustment problems [8]. Gambling may affect and change the family dynamics: the gambling parent might neglect their children by leaving them unattended while gambling [8,10], or a shift in family responsibility may occur as children take control of the family's financial situation and the role of a caregiver, or distance themselves from a gambling parent $[1,8]$. Only a few studies have explored how an adult child's problem gambling affects parents [24,25].

Parents and grandparents of a problem gambler report diminished enjoyment of life, physical and emotional stress-related symptoms, financial harms, and relationship harms. Trying to help by lending money or paying the gambler's debts or dealing with the loss of money or sold household items is common and causes mixed harms to AOs.

\subsection{GRHs for Affected Non-Family Members}

Although AFMs experience GRHs more often and to a greater degree than an affected non-family member (ANF), ANFs still experience a substantial amount of GRHs. According to previous studies, the person experiencing GRH is most often a close friend of a problem gambler [18,26], yet very little is known about how problem gambling affects friends of a gambler. However, one's own gambling participation as well as one's own gambling problem and risky alcohol consumption are linked with being a friend of the person with a problem gambling [19].

GRHs at the workplace are identified by numerous studies, which conclude that gambling at work means that the worker is not fulfilling their part of the employment agreement. Gambling even during leisure time may affect work performance (inefficient 
work), absenteeism, and tardiness at work-being preoccupied with gambling at work and experiencing withdrawal symptoms or asking for loans from co-workers [26-30].

Previous research concerning GRHs of AOs has focused mainly on the problem gambler's family, especially the partner's experiences, while little is known from the perspective of ANFs. Besides, ANFs (namely friends) have been recognized better than other non-family members. Our aim is to explore the prevalence of being an $\mathrm{AO}$ of a problem gambler by gender, and the amount and type of GRHs for subgroups of AOs and to characterize unique GRH profiles for AO subgroups.

\section{Methods}

\subsection{Data Collection}

In this study, we use the first wave of data from the population-based Finnish Gambling Harms Survey $[19,30]$ conducted by the Finnish Institute for Health and Welfare. The data were collected by Statistics Finland and portrays the situation in three Finnish regions (Uusimaa, Pirkanmaa, and Kymenlaakso) during the year 2016.

The data were collected between January and March 2017 from adults aged 18 years and over. Both web and postal surveys were available in both official languages, Finnish and Swedish. A total of 20,000 potential participants were randomly selected from the population information system and were invited to the study with an invitation letter and a brochure. Oversampling 18 to 24-year-olds compensated for the low participation rate expected based on previous surveys [20]. Persons living in institutions, such as prisoners and the infirm, were excluded. Furthermore, non-eligible individuals $(n=67)$ were removed from the sample. Therefore, the final sample consisted of 19,933 persons. The final response rate was $36.1 \%$ since 7186 adults participated in the survey.

Of the respondents, $71 \%(n=5084)$ participated using the online survey, whereas $29 \%$ $(n=2102)$ participated through the postal survey [31]. Women and older respondents were more active in taking part, whereas men and younger respondents were more reluctant to participate [19]. Ultimately, almost half $(48 \%)$ of the respondents were men, and the average age of respondents was 49 years $(S D=18.4)$ [19].

\subsection{Affected Others}

Affected others (AOs) were evaluated by inquiring: "During the year 2016, has there been a person in your life that you consider gambles too much?" [31,32]. If the person responded affirmatively, the following question was asked: "What is this person's relationship to you?" Ten options for AOs were available: (1) Spouse/partner, (2) parent/stepparent, (3) child/stepchild, (4) other person (in your household), (5) other family member (not in your household), (6) ex-partner, (7) work colleague, (8) friend, (9) neighbor, and (10) other person. First, three variables were created to indicate whether the respondent was an AO (options 1-10), AFM (options 1-3 or 5-6), or ANF (options 4 or 7-10). In addition, single response options were recoded due to the small number of respondents in some subcategories (Tables 1-3. No results were reported if the frequency was less than 5.

Table 1. The proportion of affected others (AOs) in 2016 and the problem gambler's relationship to the AO by gender.

\begin{tabular}{|c|c|c|c|c|c|c|c|}
\hline & \multicolumn{2}{|c|}{$\begin{array}{l}\text { All Respondents } \\
\quad(n=7186)\end{array}$} & \multicolumn{2}{|c|}{$\begin{array}{l}\text { Females } \\
(n=3760)\end{array}$} & \multicolumn{2}{|c|}{$\begin{array}{c}\text { Males } \\
(n=3426)\end{array}$} & \multirow[b]{2}{*}{$p$} \\
\hline & $n$ & $\%$ & $n$ & $\%$ & $n$ & $\%$ & \\
\hline $\mathrm{AO}$ & 894 & 12.9 & 522 & 13.7 & 372 & 12.1 & 0.046 \\
\hline AFM & 390 & 5.6 & 277 & 7.4 & 113 & 3.6 & $\leq 0.001$ \\
\hline Partner or ex-partner & 132 & 1.9 & 94 & 2.5 & 38 & 1.2 & $\leq 0.001$ \\
\hline Parent or step-parent & 108 & 1.7 & 75 & 2.1 & 33 & 1.1 & $\leq 0.001$ \\
\hline Child or stepchild & 54 & 0.8 & 41 & 1.1 & 13 & 0.4 & $\leq 0.001$ \\
\hline Other family member & 120 & 1.7 & 85 & 2.2 & 35 & 1.1 & $\leq 0.001$ \\
\hline ANF & 574 & 8.4 & 294 & 7.7 & 280 & 9.2 & 0.019 \\
\hline
\end{tabular}


Table 1. Cont.

\begin{tabular}{|c|c|c|c|c|c|c|c|}
\hline & \multicolumn{2}{|c|}{$\begin{array}{c}\text { All Respondents } \\
(n=7186)\end{array}$} & \multicolumn{2}{|c|}{$\begin{array}{l}\text { Females } \\
(n=3760)\end{array}$} & \multicolumn{2}{|c|}{$\begin{array}{c}\text { Males } \\
(n=3426)\end{array}$} & \multirow[b]{2}{*}{$p$} \\
\hline & $n$ & $\%$ & $n$ & $\%$ & $n$ & $\%$ & \\
\hline Friend & 317 & 4.6 & 145 & 3.7 & 172 & 5.7 & $\leq 0.001$ \\
\hline Co-worker & 86 & 1.4 & 28 & 0.8 & 58 & 2.0 & $\leq 0.001$ \\
\hline Other ${ }^{a}$ & 215 & 3.0 & 128 & 3.4 & 87 & 2.5 & 0.032 \\
\hline
\end{tabular}

The proportion of affected others (AOs) in 2016 and the problem gambler's relationship to the AO by gender. AO = affected other; $\mathrm{AFM}=$ affected family member; ANF = affected non-family member. The data $(n=7186$; non-weighted) were weighted based on gender, age, and region of residence. Significance $(p)$ was determined using Fisher's exact test. ${ }^{a}$ The category includes neighbors, other non-family members living in the same household, and all undefined persons. Note: it is possible that the respondents have several problem gamblers in their life, both in the family and outside the family.

Table 2. The type of gambling-related harms in 2016 by harm category among affected others (AOs).

\begin{tabular}{|c|c|c|c|c|c|c|c|}
\hline \multirow[b]{2}{*}{ Harm Type } & \multirow[b]{2}{*}{$\begin{array}{c}\text { Has a Gambling Problem of Your Close One(s) Caused } \\
\text { You: }\end{array}$} & \multicolumn{2}{|c|}{ AOs } & \multicolumn{2}{|c|}{ AFMs } & \multicolumn{2}{|c|}{ ANFs } \\
\hline & & $n=894$ & $\%$ & $n=390$ & $\%$ & $n=574$ & $\%$ \\
\hline Any harm & & 378 & 41.7 & 220 & 56.5 & 192 & 33.0 \\
\hline \multirow[t]{4}{*}{ Emotional harm } & Any emotional harm & 261 & 28.7 & 167 & 43.1 & 118 & 20.2 \\
\hline & Worry about the health or well-being of other close ones & 150 & 16.5 & 87 & 22.8 & 81 & 13.6 \\
\hline & $\begin{array}{l}\text { Emotional distress, such as stress, restlessness, anxiety, } \\
\text { depression, hopelessness, or guilt }\end{array}$ & 135 & 14.7 & 98 & 24.8 & 51 & 8.8 \\
\hline & Worry about health or well-being of your own child & 47 & 4.9 & 38 & 9.3 & 13 & 2.2 \\
\hline \multirow[t]{3}{*}{ Relationship harm } & Any relationship harm & 118 & 12.9 & 74 & 18.8 & 59 & 10.3 \\
\hline & $\begin{array}{l}\text { Problems in a relationship, such as arguments, distrust, } \\
\text { divorce, or separation }\end{array}$ & 60 & 6.4 & 42 & 10.5 & 22 & 3.5 \\
\hline & $\begin{array}{l}\text { Other interpersonal relationship problems, such as } \\
\text { arguments, isolation, distancing yourself from friends }\end{array}$ & 78 & 8.8 & 45 & 11.8 & 45 & 8.0 \\
\hline \multirow[t]{3}{*}{ Financial harm } & Any financial harm & 73 & 8.4 & 37 & 10.3 & 44 & 7.6 \\
\hline & Eviction or a threat of being evicted & 16 & 1.8 & 7 & 1.8 & 11 & 2.0 \\
\hline & $\begin{array}{l}\text { Other financial problems, such as payment issues, loans } \\
\text { related to gambling, loss of financial credibility }\end{array}$ & 69 & 7.9 & 35 & 9.8 & 42 & 7.3 \\
\hline \multirow[t]{4}{*}{ Social deviance harm } & Any social deviance harm & 16 & 1.8 & 7 & 1.8 & 10 & 1.8 \\
\hline & $\begin{array}{l}\text { Emotional violence, such as blackmailing, pressuring, } \\
\text { and intimidation }\end{array}$ & 12 & 1.3 & 6 & 1.5 & 7 & 1.3 \\
\hline & Physical violence witnessed or being threatened & 10 & 1.2 & .. & .. & .. & .. \\
\hline & $\begin{array}{l}\text { Victim of some other type of crime, for example, theft or } \\
\text { identity theft }\end{array}$ & 9 & 0.9 & 5 & 1.3 & 5 & 0.5 \\
\hline Health harm & $\begin{array}{l}\text { Health impacts, such as sleep problem, headaches, } \\
\text { backaches, or stomach aches }\end{array}$ & 42 & 4.7 & 31 & 8.0 & 18 & 3.0 \\
\hline Work/study harm & Work- or study-related harm & 18 & 2.1 & 5 & 1.3 & 14 & 2.7 \\
\hline Undefined harm & Other harm, please specify ${ }^{a}$ & 84 & 9.1 & 41 & 10.0 & 47 & 8.0 \\
\hline
\end{tabular}

$\mathrm{AO}=$ affected other; $\mathrm{AFM}=$ affected family member; $\mathrm{ANF}=$ affected non-family member. The AOs in the data $(n=894$, non-weighted $)$ were weighted based on gender, age, and region of residence. ${ }^{a}$ Undefined harms included loss of time and money, undefined feelings of pity and grief, worry, and self-destructive thoughts. Note: it is possible that the respondents have several different problem gamblers in their life, both in the family and outside the family; Data not available or too uncertain for presentation or subject to secrecy.

Table 3. The type of gambling harms in 2016 for the AOs by the problem gambler's relationship to the AO.

\begin{tabular}{|c|c|c|c|c|c|c|c|c|}
\hline \multirow{3}{*}{$\begin{array}{l}\text { Has a Gambling Problem of } \\
\text { Your Close One(s) Caused You: }\end{array}$} & \multicolumn{5}{|c|}{$\begin{array}{l}\text { Affected Family Members (AFMs) } \\
\qquad(n=390)\end{array}$} & \multicolumn{3}{|c|}{$\begin{array}{l}\text { Affected Non-Family Members (ANFs) } \\
\qquad(n=574)\end{array}$} \\
\hline & Partner & Ex-Partner & $\begin{array}{l}\text { Parent or } \\
\text { Step-Parent }\end{array}$ & $\begin{array}{l}\text { Child or } \\
\text { Stepchild }\end{array}$ & $\begin{array}{l}\text { Other Family } \\
\text { Member }\end{array}$ & Friend & Co-Worker & Other * \\
\hline & $n=132$ & $n=21$ & $n=108$ & $n=54$ & $n=120$ & $n=317$ & $n=86$ & $n=214$ \\
\hline 1. Financial harm & 14.4 & 26.1 & 5.9 & 11.1 & 10.0 & 7.5 & 9.1 & 8.4 \\
\hline 2. Emotional harm & 32.3 & 45.8 & 37.3 & 60.0 & 51.7 & 21.5 & 14.1 & 21.9 \\
\hline 3. Relationship harm & 29.3 & 26.1 & 11.9 & 11.1 & 20.0 & 10.8 & 11.1 & 13.5 \\
\hline 4. Health harm & 10.5 &.. & 5.9 & 11.1 & 8.3 & 3.3 &.. & 3.7 \\
\hline 5. Work/study harm &.. &.. &.. &.. &.. & 1.5 & 6.1 & 4.2 \\
\hline 6. Social deviance harm &.. &.. & .. & .. & .. & 1.5 &.. & .. \\
\hline Any harm & 49.6 & 70.8 & 50.0 & 64.8 & 64.2 & 32.9 & 33.0 & 35.3 \\
\hline
\end{tabular}

The numbers are percentages. $\mathrm{AO}=$ affected other. The AOs in the data $(n=894$, non-weighted $)$ were weighted based on gender, age, and region of residence. * The category includes neighbors, other persons living in the same household, and other undefined persons. Note: it is possible that the respondents have several different problem gamblers in their life, both in the family and outside the family; Data not available or too uncertain for presentation, or subject to secrecy.

GRHs for AOs were questioned using 12 response options [18]. In addition to an open-ended response option, a question about work/study-related harm was added. 
Furthermore, a new variable indicating the amount of GRHs was recoded (Figure 1). Harm categories and the individual items described the type of GRHs.

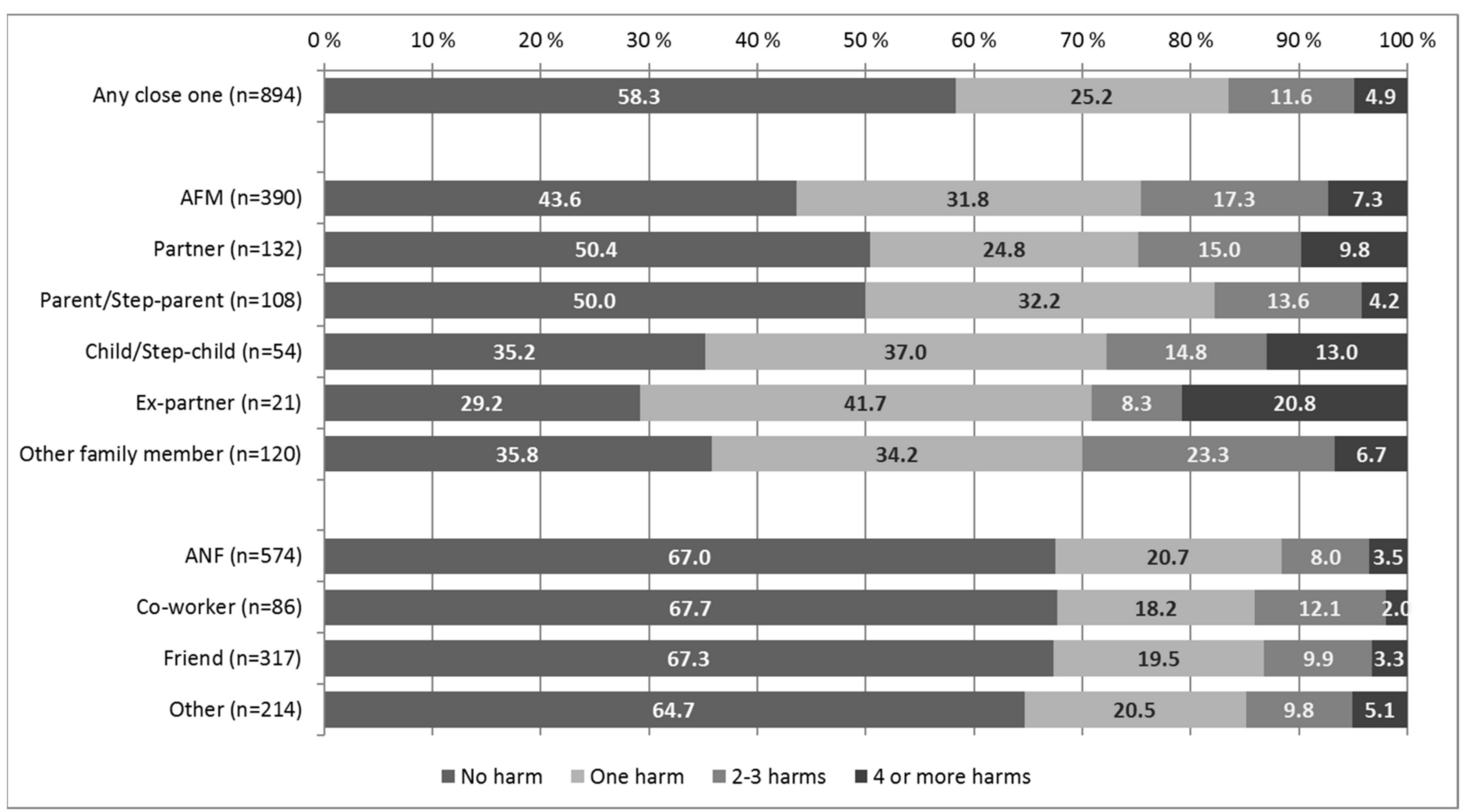

Figure 1. The amount of gambling harms for the AOs (n) by the problem gambler's relationship to the AO.

In addition, the data contained register-based information about the respondents' gender and age. Age was dichotomized into two age groups: 18-34, and 35 and up.

\subsection{Data Analyses}

The age, gender, and regional distributions were used to calibrate the data weights. Percentages and significance $(p)$ were calculated with Chi-Squared and Fisher's exact tests. All selected variables were dichotomized and added simultaneously into the logistic regression models. Furthermore, health-related harms, work/study harms, and social deviance harms were combined for the model and named other harms due to the small number of respondents in some subcategories. To optimize the model, gender and age were added. All analyses were done using SPSS version 27.0 (IBM Corporation, Chicago, IL, USA).

\section{Results}

\subsection{The Proportion of AOs and the Problem Gambler's Relationship to the AO}

Of all respondents, $12.9 \%$ had at least one person in 2016 who they considered a problem gambler (Table 1). The proportion of AOs was significantly higher among women $(13.7 \%)$ than men $(12.1 \%)$. The proportion of past-year ANFs was $8.4 \%$, while the corresponding figure for the AFMs was 5.6\%. Overall, being an AFM was more common (7.4\%) among women than among men $(3.6 \%)$, whereas being an ANF was more common among men $(9.2 \%)$ than among women $(7.7 \%)$. One percent of all respondents were both AFMs and ANFs.

Among AFMs, the problem gambler was most commonly a partner or ex-partner $(1.9 \%)$ or a parent or step-parent $(1.7 \%)$. Among ANFs, the problem gambler was most commonly a friend $(4.6 \%)$ or a co-worker $(1.4 \%)$. The proportion of those with a friend and co-worker with a gambling problem was higher among men. 


\subsection{The Amount of GRHs for the AOs}

More than half $(58.3 \%)$ of the AOs did not experience any harm (Figure 1$)$. Among AFMs, the proportion of those experiencing no harm was $43.6 \%$, while the corresponding proportion among ANFs was $67.0 \%$. Four or more harms were experienced most frequently by the AFMs (7.3\%). Among AFMs, those with a child or stepchild (13.0\%) or partner $(9.8 \%)$, and particularly an ex-partner $(20.8 \%)$ most often experienced at least four harms. Among ANFs, the proportion of those experiencing four or more harms varied between $2.0 \%$ and $5.1 \%$.

\subsection{The Type of GRH by Harm Category}

Emotional harms, relationship harms, and financial harms were the three most common types of past-year harms for AOs-both AFMs and ANFs (Table 2). Among the AOs, the most common individual harms caused by close ones' problem gambling were worry about the health or well-being of other close ones (16.5\%), emotional distress (14.7\%), and other interpersonal relationship problems, such as arguments, isolation, and distancing from a friend $(8.8 \%)$. Furthermore, undefined harms, such as loss of time and money, undefined feelings of pity and grief, worry, or self-destructive thoughts were experienced by one in ten $(9.1 \%)$. Overall, the proportions of harm for AFMs were mostly higher than those of ANFs, except for work- and study-related harms. Among AFMs, $1.3 \%$ had experienced such harms while the corresponding proportion among ANFs was $2.7 \%$.

Of family members, the highest prevalence of experiencing at least one harm type was among those with ex-partners $(70.8 \%)$, a child or stepchild $(64.8 \%)$, or other family members $(64.2 \%)$ with a gambling problem (Table 3$)$. The proportion of those experiencing at least one financial harm was highest among those with an ex-partner with a gambling problem $(26.1 \%)$. On the other hand, the proportion of those experiencing at least one emotional harm was highest among those having a child or stepchild with a gambling problem $(60.0 \%)$, while relationship harms were most common with partners and expartners. Of non-family members, about one in three (32.9-35.3\%) had experienced at least one harm-most commonly emotional harms.

The odds of experiencing financial harms were significantly increased for 18 to 34-year-olds (OR 1.82) and for those whose partner or ex-partner had a gambling problem (OR 3.91) (Table 4). Furthermore, having a parent or step-parent (OR 1.93) and child or stepchild (OR 3.64) increased the odds of experiencing emotional harm, whereas male gender (OR 0.50) and being an ANF (OR 0.58) decreased the odds of experiencing emotional harm. Those whose partner (OR 5.07) or ex-partner (OR 1.97) had a gambling problem had increased odds of experiencing relationship harm. Moreover, the odds of experiencing other harms - either social deviance harm, work- or study-related harm, or health harm — were increased if one had a partner (OR 3.31) or ex-partner (OR 2.99) with a gambling problem.

Table 4. Logistic regression models on the association between different harm categories and relationship to the AO.

\begin{tabular}{|c|c|c|c|c|c|c|c|c|}
\hline & \multicolumn{2}{|c|}{ Financial Harms } & \multicolumn{2}{|c|}{ Emotional Harms } & \multicolumn{2}{|c|}{ Relationship Harms } & \multicolumn{2}{|c|}{ Other Harms a } \\
\hline & OR & $95 \% \mathrm{CI}$ & OR & $95 \% \mathrm{CI}$ & OR & $95 \% \mathrm{CI}$ & OR & $95 \% \mathrm{CI}$ \\
\hline Male (ref. female) & 1.31 & $0.80-2.15$ & $0.50^{* * *}$ & $0.36-0.69$ & 0.77 & $0.50-1.18$ & 1.10 & $0.62-1.94$ \\
\hline $\begin{array}{c}18 \text { to 34-year-old (ref. 35-74) } \\
\text { AFM }\end{array}$ & $1.82 * *$ & $1.11-2.99$ & 1.35 & $0.99-1.86$ & 1.50 & $0.99-2.25$ & 1.33 & $0.75-2.36$ \\
\hline Partner or ex-partner & $3.91 * * *$ & $1.95-7.83$ & 1.03 & $0.61-1.75$ & $5.07^{* * *}$ & $2.78-9.24$ & $3.31 * *$ & $1.58-6.97$ \\
\hline $\begin{array}{l}\text { Parents or step-parent or other family } \\
\text { member }\end{array}$ & 1.51 & $0.77-2.95$ & $1.93^{* *}$ & $1.19-3.10$ & $1.97^{*}$ & $1.12-3.46$ & 1.75 & $0.85-3.61$ \\
\hline Child or stepchild & 2.29 & $0.87-6.02$ & $3.64^{* * *}$ & $1.84-7.19$ & 0.98 & $0.38-2.56$ & $2.99 *$ & $1.14-7.82$ \\
\hline $\mathrm{ANF}$ & 1.35 & $0.68-2.67$ & $0.55 * *$ & $0.34-0.89$ & 1.32 & $0.74-2.33$ & 1.20 & $0.58-2.51$ \\
\hline Log-likelihood & 510.5 & & 1008.9 & & 669.1 & & 421.6 & \\
\hline LR Chi 2 & 22.6 & & 106.1 & & 46.6 & & 16.3 & \\
\hline$p$ & 0.001 & & 0.000 & & 0.000 & & 0.012 & \\
\hline Nagelkerke R & 0.055 & & 0.154 & & 0.091 & & 0.046 & \\
\hline
\end{tabular}

$\mathrm{AO}=$ affected other. $\mathrm{AFM}=$ affected family member. $\mathrm{ANF}=$ affected non-family member. The AOs in the data $(n=894$, non-weighted $)$ were weighted based on gender, age, and region of residence. ${ }^{a}$ Includes social deviance harm, work, or study-related harm and health harm. ${ }^{*} p<0.05 ;{ }^{* *} p<0.01 ; * * * 0.001$. 


\section{Discussion}

This study explored the prevalence of being an $\mathrm{AO}$ of a problem gambler by gender. In addition, it focused on the amount and type of GRHs for AOs, including both AFMs and ANFs, and distinguished the GRH profiles for AO subgroups. A past-year time frame was used; therefore, this study differs from previous Finnish studies on the same topic, which were conducted using a lifetime frame $[11,14,19]$.

As expected, the AFMs were typically women. However, ANFs (including both friends and co-workers) were typically men. Similar gender differences have been seen among both the general population $[14,19,21,32]$ and in treatment settings. In the latter context, women AOs-especially affected female partners and mothers-have been extensively represented [33-39]. ANFs were typically men, thus rarely observed as seeking help for themselves as AOs. Help-seeking behavior is plausible when further exploring the type and prevalence of harms experienced by AFMs and ANFs.

Our results confirmed that emotional harms, relationship harms, and financial harms were the three most common types of past-year harms for the AOs $[5,10,11]$. Different types of harms may be interconnected and boost each other. For example, a financial burden may intensify relationship and emotional harms. The above-mentioned harms were among the top three with both the AFMs and the ANFs; but in general, the ANFs experienced fewer harms than the AFMs. This finding makes sense since the nature of the relationship between the ANF and the problem gambler is generally assumed to be more distant than the relationship with the AFM, at least considering finances.

Emotional harms were experienced largely by AFMs (43.1\%) and less than half by ANFs (21.1\%). Based on previous research, affected partners report that gambling impacts their daily life and brings distress, a desire to escape the relationship, a sense of hopelessness, and helplessness [12]. It is obvious that the worry and stress of a problem gambler's overall life course, including possible criminal acts and the financial situation, impose an emotional burden and affect one's own well-being.

In our study, emotional harms were most common and enhanced if the child or stepchild or partner or ex-partner was the problem gambler. This implies that emotional harm may be perceived differently, depending on the type and depth of the relationship but also depending on the distance from the gambler. For example, a person living in the same household with a problem gambler may experience distress to handle the household finances and daily errands because the gambling problem may limit a person's ability to commit and share duties equally. Additionally, family members living with a problem gambler may have to constantly face the GRHs without any possibility to withdraw.

Affected partners and also ex-partners came across various harms rather commonly. Based on our model, relationship and financial harms were exceptionally frequent among the affected partners or ex-partners. Relationship harms have been reported by partners as being five to six times higher than the gambler's perception of the state of the relationship [20]. These differences may be affected by the gambler's preoccupation with gambling, which manifests in lower interest in relationships in general [40]. The severity of this domain of harm should be acknowledged, particularly with partners, since it may and often does lead to the end of the relationship [12,41].

Around one in ten AOs had experienced financial harms. Being an affected partner often means taking responsibility for running the household finances [42]. In some cases, it even means taking on extra employment, paying the partner's debts to overcome financial difficulties [15,21] or facing indebtedness and creditor issues [1]. Being an affected partner can influence work performance, and prolonged distress may lead to poor mental health and risky alcohol consumption $[15,21]$. Financial harms, such as loans or the consequences of bankruptcy may even follow along long after a separation or divorce. The continuation of the gambler's financial struggle may also negatively affect the ex-partners' and mutual children's long-term quality of life with delays in child support payments or child neglect.

On the other hand, gambling and problem gambling can occur anywhere, even in the workplace. The proportions of harms for ANFs were mostly lower than those of AFMs, 
but work- and study-related harms were more common among the ANFs. In fact, there are some specific work fields-such as the transport sector, shift work, building, construction and service, monotonous manual indoor work, and work that requires frequent traveling $[27,28,30]$ where the prevalence of gambling at work is higher than average. Above all, employees working at gambling venues have high rates of gambling participation and problem gambling [43]. Exposure to gambling at work, and also in connection to work (i.e., close proximity to gambling venues), may expose one to gambling at lunch breaks, for example [30]. Gambling can also be a part of the workplace culture and, in this way, it can fuel an existing gambling problem [27]. Overall, the harms for the ANFs were not as significant as the harms for the AFMs. Yet, it should not be overlooked. For a friend, it may mean constant worry about the gambler's overall well-being, the disappointment of neglecting a friendship, and the strain that problem gambling causes for the gambler.

\subsection{Implications for Practices and Further Studies}

As per our results, GRHs vary in different subgroups. The first point is to increase public and professionals' awareness of the gambling phenomena (i.e., problem gambling can cause harms to people close to the gambler) and to lower the bar of directly asking whether such a problem exists. The availability of low-threshold support or treatment options for AOs is still non-existent or limited, at least in Finland. Not all AOs report GRHs, and in turn, we do not know well enough who are the AOs that require support and what type of support; thus, this is an area worth investigating in the future. It could well be that the psychoeducational components of problem gambling (understanding a gambler), securing one's own finances, and building clear boundaries to secure one's own well-being delivered online as self-help [34,39,44] may be a suitable support for this subgroup. Overall, AOs may use self-help strategies that focus on changing their own behavior, particularly taking responsibility for the family's finances [3]. Moreover, AOs may use strategies to support their close ones to change their gambling behavior by telling them how their gambling has impacted the family, for example. These self-help strategies can be matched with other support and treatments.

Furthermore, recognizing gambling in the workplace can be challenging since people are often not aware of the magnitude of gambling problems or even that the person close to them is gambling [25] due to its hidden nature. Clear guidelines of how an affected friend, co-worker, or family member can recognize and support the person with a gambling problem already exist [45] and can be used as guidelines in community training targeted to the wider public [46]. In a workplace, clear guidelines are recommended to be followed the same as workplace guidelines for a worker being at the workplace under the influence of alcohol or other drugs. Preventive and harm minimization strategies at the workplace, especially those workplaces that are at greater risk [27], should be put in place. Yet, we know little about how an adult child's gambling affects the parents' well-being, and that would be an important subgroup to explore more in depth.

It would be useful for policy makers to understand to what extent emotional, financial, and health harms are more widespread and prevalent than the ones experienced solely by the gamblers themselves. In fact, it has been estimated that problem gambling affects approximately six persons per gambler [13].

\subsection{Limitations}

In this study, only the personal views of AOs of problem gamblers were recorded, and no validated instrument was used. The prevalence rates of AOs were assessed using self-assessment method and a life-time frame. Even though it would be interesting to compare the prevalence of AOs along with the prevalence rate of problem gambling from the gamblers perspective, the comparison is not advisable due to the methodological differences. For example, the prevalence rate of problem gambling has been around 3 percent in Finland, but the South Oaks Gambling Screen was used with a past-year time frame. Furthermore, many subgroups of respondents and subcategories of GRHs were 
combined for the models due to low frequencies. Overall, the results are presented only if the frequency in the subcategory was above five, and this may have meant missing some detailed information. Additionally, non-significant findings may be explained by the small number of participants in some subgroups, even though the corresponding OR suggests an association between the variables. In our study, respondents could choose multiple options for the question about the respondent's relation to the person with a gambling problem. Therefore, although the same question was used on our respondents, the results are not directly comparable with the results of the previous two studies where respondents were advised to choose only one option [31,32].

\section{Conclusions}

The AFMs were typically women, and ANFs (including both friends and co-workers) were typically men. Emotional harms, relationship harms, and financial harms were the three most common types of past-year harms for the AOs. Affected partners experienced various harms and rather commonly. Relationship and financial harms were exceptionally typical among both affected partners and ex-partners. Emotional harms were utmost distinctive. The most common and notable emotional harms were if the child or stepchild or partner/ex-partner was the problem gambler. About one in ten AOs had experienced financial harms. Even though the proportions of harms for ANFs were mainly lower than those of AFMs, the work- and study-related harms were more common among the ANFs. Given the significant proportion of AOs and the variety of GRHs they encounter regardless of subgroups, there is a need to implement preventive efforts, community training, and tailored intervention to minimize the harms of AOs.

Author Contributions: Conceptualization and planning: S.C., K.L., A.H.S.; Methodology: K.L., H.H., A.H.S.; Formal Analysis: K.L., H.H.; Writing: S.C., K.L., H.H., A.H.S.; Review and editing: S.C., K.L., H.H., A.H.S.; Visualization: K.L., H.H.; Supervision: S.C., A.H.S. Project administration: A.H.S. All authors have read and agreed to the published version of the manuscript.

Funding: The Finnish Gambling Harms survey and the daily work of the authors (S.C., K.L., A.H.S.) were funded by the Ministry of Social Affairs and Health, Finland, within the objectives of the $\$ 52$ Appropriation of the Lotteries Act. However, it had no role in the study design, analysis, or interpretation of the results of the manuscript or any phase of the publication process. In addition, $\mathrm{HH}$ and KL received personal grants based on funding from the Ministry of Social Affairs and Health, Finland, but granted by the Finnish Foundation for Alcohol Studies.

Institutional Review Board Statement: The research protocol was favored in 2016 by the Ethics Committee of the Finnish Institute for Health and Welfare (Statement THL/1390/6.02.01/2016). Written information about the study and the principles of voluntary participation were offered to potential participants. According to the prevailing national data protection regulations, potential participants were informed that participating in the study included links to the register.

Informed Consent Statement: The invitation letter sent to the participants included a link to the online survey and personal participation code for those willing to participate, thus informed consent was obtained from all subjects involved in the study.

Data Availability Statement: The survey data without any register-based information is publicly accessible for research purposes from the Finnish Society Science Data Archive (FSD) with the name of Rahapelikysely 2016 (FSD3261), urn:nbn:fi:fsd:T-FSD3261.

Acknowledgments: The authors wish to thank the Ministry of Social Affairs and Health for funding, statistician Jukka Kontto for his tips, and Lingsoft language services for linguistic assistance.

Conflicts of Interest: All authors (S.C.; K.L.; H.H.; A.H.S.) declare that they have no conflicts of interest. 


\section{References}

1. Langham, E.; Thorne, H.; Browne, M.; Donaldson, P.; Rose, J.; Rockloff, M. Understanding gambling related harm: A proposed definition, conceptual framework, and taxonomy of harms. BMC Public Health 2016, 16, 80. [CrossRef]

2. Browne, M.; Rawat, V.; Tulloch, C.; Murray-Boyle, C.; Rockloff, M. The Evolution of Gambling-Related Harm Measurement: Lessons from the Last Decade. Int. J. Environ. Res. Public Health 2021, 18, 4395. [CrossRef]

3. Booth, N.; Dowling, N.A.; Landon, J.; Lubman, D.I.; Merkouris, S.S.; Rodda, S.N. Affected Others Responsivity to Gambling Harm: An International Taxonomy of Consumer-Derived Behaviour Change Techniques. J. Clin. Med. 2021, 10, 583. [CrossRef]

4. Browne, M.; Bellringer, M.; Greer, N.; Kolandai-Matchett, K.; Langham, E.; Rockloff, M.; Du Preez, K.; Abbott, M. Measuring the Burden of Gambling Harm in New Zealand; Ministry of Health: Wellington, New Zealand, 2017.

5. Dowling, N.; Rodda, S.; Lubman, D.; Jackson, A. The impacts of problem gambling on concerned significant others accessing web-based counselling. Addict. Behav. 2014, 39, 1253-1257. [CrossRef]

6. Hing, N.; Tiyce, M.; Holdsworth, L.; Nuske, E. All in the Family: Help-Seeking by Significant Others of Problem Gamblers. Int. J. Ment. Health Addict. 2013, 11, 396-408. [CrossRef]

7. Lee, B.; Awosoga, O. Congruence Couple Therapy for pathological gambling: A pilot randomized controlled trial. J. Gambl. Stud. 2015, 31, 1047-1068. [CrossRef]

8. Riley, B.J.; Harvey, P.; Crisp, B.R.; Battersby, M.; Lawn, S. Gambling-related harm as reported by concerned significant others: A systematic review and meta-synthesis of empirical studies. J. Fam. Stud. 2018, 27, 112-130. [CrossRef]

9. Kourgiantakis, T.; Hussain, A.; Ashcroft, R.; Logan, J.; McNeil, S.; Williams, C.C. Recovery-oriented social work practice in mental health and addictions: A scoping review protocol. BMJ Open 2020, 10, e037777. [CrossRef] [PubMed]

10. Li, E.; Browne, M.; Rawat, V.; Langham, E.; Rockloff, M. Breaking Bad: Comparing Gambling Harms Among Gamblers and Affected Others. J. Gambl. Stud. 2016, 33, 223-248. [CrossRef] [PubMed]

11. Lind, K.; Castrén, S.; Hagfors, H.; Salonen, A.H. Harm as reported by affected others: A population-based cross-sectional Finnish Gambling 2019 study. Manuscript submitted to publication.

12. Jeffrey, L.; Browne, M.; Rawat, V.; Langham, E.; Li, E.; Rockloff, M. Til debt do us part: Comparing gambling harms between gamblers and their spouses. J. Gambl. Stud. 2019, 35, 1015-1034. [CrossRef] [PubMed]

13. Goodwin, B.C.; Browne, M.; Rockloff, M.; Rose, J. A typical problem gambler affects six others. Int. Gambl. Stud. 2017, 17, 276-289. [CrossRef]

14. Salonen, A.H.; Castreén, S.; Alho, H.; Lahti, T. Concerned significant others of people with gambling problems in Finland: A cross-sectional population study. BMC Public Health 2014, 14, 1471-2458. [CrossRef] [PubMed]

15. Svensson, J.; Romild, U.; Shepherdson, E. The concerned significant others of people with gambling problems in a national representative sample in Sweden-A 1-year follow-up study. BMC Public Health 2013, 13, 1087. [CrossRef]

16. Wenzel, H.G.; Øren, A.; Bakken, I.J. Gambling problems in the family-A stratified probability sample study of prevalence and reported consequences. BMC Public Health 2008, 8, 412. [CrossRef]

17. Abbott, M.; Bellringer, M.; Garrett, N.; Mundy-McPherson, S. New Zealand 2012 National Gambling Study: Gambling Harm and Problem Gambling; Ministry of Health: Wellington, New Zealand, 2014.

18. Salonen, A.H.; Alho, H.; Castreén, S. Gambling frequency, gambling problems and concerned significant others of problem gamblers in Finland: Cross-sectional population studies in 2007 and 2011. Scand. J. Public Health 2015, 43, 229-235. [CrossRef]

19. Salonen, A.H.; Hellman, M.; Latvala, T.; Castrén, S. Gambling participation, gambling habits, gambling related harm, and opinions on gambling advertising in Finland in 2016. Nord. Stud. Alcohol Drugs 2018, 35, 215-234. [CrossRef] [PubMed]

20. Salonen, A.; Raisamo, S. Suomalaisten Rahapelaaminen 2015-Rahapelaaminen, Rahapeliongelmat ja Rahapelaamiseen Liittyvät Asenteet ja Mielipiteet 15-74-Vuotiailla; THL: Helsinki, Finland, 2015.

21. Holdsworth, L.; Nuske, E.; Tiyce, M.; Nerilee, H. Impacts of gambling problems on partners: Partners' interpretations. Asian J. Gambl. Issues Public Health 2013, 3, 1-14. Available online: http:/ / www.ajgiph.com/content/3/1/11 (accessed on 20 June 2021). [CrossRef]

22. Dowling, N.; Suomi, A.; Jackson, A.; Lavis, T.; Patford, J.; Cockman, S.; Abbot, M. Problem Gambling and Intimate Partner Violence: A systematic review and meta-analysis. Trauma Violence Abus. 2016, 17, 43-61. [CrossRef]

23. Dowling, N.A.; Ewin, C.; Youssef, G.J.; Merkouris, S.S.; Suomi, A.; Thomas, S.A.; Jackson, A.C. Problem gambling and family violence: Findings from a population-representative study. J. Behav. Addict. 2018, 7, 806-813. [CrossRef]

24. Landon, J.; Grayson, E.; Roberts, A. An exploratory study of the impacts of gambling on affected others accessing a social service. Int. J. Ment. Health Addict. 2018, 16, 573-587. [CrossRef]

25. Patford, J. The yoke of care: How parents and parents-in-law experience, understand and respond to adult children's gambling problems. Aust. J. Prim. Health 2007, 13, 59-68. [CrossRef]

26. Binde, P. Preventing and responding to gambling-related harm and crime in the workplace. Nord. Stud. Alcohol Drugs 2016, 33, 247-266. [CrossRef]

27. Binde, P.; Romild, U. Risk of problem gambling among occupational groups: A population and registry study. Nord. Stud. Alcohol Drugs 2020, 37, 262-278. [CrossRef]

28. Dahlgren, K. Problematisk Spilleatferd i Arbeidslivet: Risikofaktorer, Mulighetsstrukturer Og Akan-Modellen; AKAN: Oslo, Norway, 2012. Available online: http:/ / akan.no/wp-content/uploads/2013/09/pengespilldahlgren.pdf (accessed on 20 June 2021). 
29. Hing, N.; Breen, H. Risk and Protective Factors Relating to Gambling by Employees of Gaming Venues. Int. Gambl. Stud. 2008, 8, 1-23. [CrossRef]

30. Revheim, T.; Buvik, K. Opportunity structure for gambling and problem gambling among employees in the transport industry. Int. J. Ment. Health Addict. 2009, 7, 217-228. [CrossRef]

31. Volberg, R.A.; Williams, R.J.; Stanek, E.J.; Houpt, K.A.; Zorn, M.; Rodriguez-Monguio, R. Gambling and Problem Gambling in Massachusetts: Results of a Baseline Population Survey; School of Public Health and Health Sciences, University of Massachusetts Amherst: Amherst, MA, USA, 2015.

32. Williams, R.J.; Pekow, P.S.; Volberg, R.A.; Stanek, E.J.; Zorn, M.; Houpt, A. Impacts of Gambling in Massachusetts: Results of a Baseline Online Panel Survey (BOPS); School of Public Health and Health Sciences, University of Massachusetts Amherst: Amherst, MA, USA, 2017.

33. Suomi, A.; Dowling, N.A.; Thomas, S.; Abbott, M.; Bellringer, M.; Battersby, M.; Koziol-McLain, J.; Lavis, T.; Jackson, A.C. Patterns of family and intimate partner violence in problem gamblers. J. Gambl. Stud. 2018, 35, 465-484. [CrossRef] [PubMed]

34. Buchner, U.G.; Koytek, A.; Wodarz, N.; Wolstein, J. Is an e-mental health programme a viable way to reach affected others of disordered gamblers? A feasibility study focusing on access and retention. Int. Gambl. Stud. 2019, 19, 85-105. [CrossRef]

35. Magnusson, K.; Nilsson, A.; Andersson, G.; Hellner, C.; Carlbring, P. Internet-delivered cognitive-behavioral therapy for significant others of treatment-refusing problem gamblers: A randomized wait-list controlled trial. J. Consult. Clin. Psychol. 2019, 87, 802-814. [CrossRef] [PubMed]

36. Nilsson, A.; Magnusson, K.; Carlbring, P.; Andersson, G.; Hellner, C. Behavioral couples therapy versus cognitive behavioral therapy for problem gambling: A randomized controlled trial. Addiction 2020, 115, 1330-1342. [CrossRef]

37. Orford, J.; Copello, A.; Velleman, R.; Templeton, L. Family members affected by a close relative's addiction: The stress-straincoping-support model. Drugs Educ. Prev. Policy 2010, 17 (Suppl. S1), 36-43. [CrossRef]

38. Tremblay, J.; Dufour, M.; Bertrand, K.; Blanchette-Martin, N.; Ferland, F.; Savard, A.C.; Saint-Jacques, M.; Côté, M. The Experience of couples in the process of treatment of pathological gambling: Couple vs. individual therapy. Front. Psychol. 2018, 8, 1-14. [CrossRef] [PubMed]

39. Rodda, S.N.; Dowling, N.A.; Thomas, A.C.; Bagot, K.L.; Lubman, D.I. Treatment for Family Members of People Experiencing Gambling Problems: Family Members Want Both Gambler-Focused and Family-Focused Options. Int. J. Ment. Health Addict. 2021, 18, 1318-1334. [CrossRef]

40. American Psychiatric Association. Diagnostic and Statistical Manual of Mental Health Disorders, 5th ed.; American Psychiatric Association: Washington, DC, USA, 2013.

41. Dickson-Swift, V.A.; James, E.L.; Kippen, S. The experience of living with a problem gambler: Spouses and partners speak out. J. Gambl. Issues 2005, 13, 1-22. [CrossRef]

42. Mathews, M.; Volberg, R. Impact of problem gambling on financial, emotional and social well-being of Singaporean families. Int. Gambl. Stud. 2013, 13, 127-140. [CrossRef]

43. Hing, N.; Nisbet, S. Testing the Link between Accessibility and Gambling Problems: Gambling and Problem Gambling Amongst Gaming Venue Staff; Department of Justice: Melbourne, Australia, 2009.

44. Makarchuk, K.; Hodgins, D.C.; Peden, N.E. Development of a Brief Intervention for Concerned Significant Others of Problem Gamblers. Addict. Disord. Treat. 2002, 1, 126-134. [CrossRef]

45. Bond, K.S.; Jorm, A.F.; Miller, H.E.; Rodda, S.N.; Reavley, N.J.; Kelly, C.M.; Kitchener, B.A. How a concerned family member, friend or member of the public can help someone with gambling problems: A Delphi consensus study. BMC Psychol. 2016, 4, 6. [CrossRef]

46. Hing, N.; Nuske, E.; Gainsbury, S.M.; Russell, A.M.T. Perceived stigma and self-stigma of problem gambling: Perspectives of people with gambling problems. Int. Gambl. Stud. 2016, 16, 31-48. [CrossRef] 